\title{
Effect of ionic liquid structure on viscoelastic behavior of hydrogen-bonded micellar ion gels
}

\author{
Ryota Tamate ${ }^{\mathrm{a}, \mathrm{b},{ }^{*}}$, Kei Hashimoto ${ }^{\mathrm{a}}$, Xiang $\mathrm{Li}^{\mathrm{c}}$, Mitsuhiro Shibayama ${ }^{\mathrm{c}}$, Masayoshi Watanabe, \\ a Department of Chemistry and Biotechnology Yokohama National University, 79-5 Tokiwadai, Hodogaya-ku, Yokohama, 240-8501, Japan \\ b National Institute for Materials Science (NIMS), 1-1 Namiki, Tsukuba, Ibaraki, 305-0044, Japan \\ ${ }^{c}$ Institute for Solid State Physics, The University of Tokyo, 5-1-5 Kashiwano-ha, Kashiwa, Chiba, 277-8581, Japan
}

\section{A R T I C L E I N F O}

Keywords

Ion gel

Block copolymer

Ionic liquid

\begin{abstract}
A B S T R A C T
Ion gels based on block copolymer self-assembly in ionic liquids (ILs) are attractive, processable, non-volatile, ion-conducting soft materials. Recently, a new class of ion gels based on hydrogen bonding between jammed block copolymer micelles in ILs that shows good mechanical strength and rapid self-healing ability has been developed. Herein, the effect of IL cation and anion structures on the microstructures and viscoelastic properties of a hydrogen-bonded micellar ion gel is reported. It was clarified that competition among cations, anions, and polymer chains for hydrogen bonding significantly affects the viscoelastic behavior of the ion gel. In the case of weak hydrogen bonding for ILs, macroscopic phase separation occurs due to strong hydrogen bonding between diblock copolymer micelles, resulting in an opaque and fragile ion gel, whereas storage and loss moduli are significantly reduced for ILs showing strong hydrogen bonding. Control of competitive hydrogen bonding interaction between polymers and ILs is thus critical to obtaining the desirable physical properties for ion gels.
\end{abstract}

\section{Introduction}

Polymer gels, consisting of three dimensionally percolating polymer networks swollen with solvents have attracted attention for many decades for their attractive properties. Recently, various novel polymer gels that show excellent functionalities such as high mechanical strength [1-5], precisely defined network structures [6-8], stimuli-responsiveness [9-12], and autonomous dynamic behaviors [13-15] have been reported. According to the solvent absorbed into the polymer network, polymer gels can be classified as hydrogels or organogels. Hydrogels, swollen with water, have been widely investigated for biomedical applications such as drug delivery systems and tissue-culturing materials [16-20]. Organogels, swollen with organic solvents, have also been studied for a long time, for use in energy storage devices, as electrolytes, and in pharmaceutical contexts [21-31].

Recently, ion gels, which are polymer networks swollen with ionic liquids (ILs), have been recognized as a third class of polymer gels that offer unique properties such as non-flammability, high thermal and electrochemical stability, negligible vapor pressure, and high ionic conductivity [32-35]. Since the combinations of cations and anions possible for the them are infinite, ILs have been recognized as "designer solvents." Physicochemical properties of ion gels can be significantly mod- ulated via the selection of suitable ILs. Among diverse strategies for fabrication of ion gels, block copolymer self-assembly in ILs is a promising way since it offers excellent tunability of the chemical composition, solution processability, and mechanical strength [36-38]. In particular, ABA triblock copolymer-based ion gels have been intensively investigated due to their high mechanical integrity. Stimuli-responsive ABA triblock copolymer ion gels showing thermoresponsivity [39-41] and photoresponsivity [42-44] have also been developed as intelligent soft materials.

More recently, we have developed a new class of ion gels based on jamming and hydrogen bonding of diblock copolymer micelles in ILs (Scheme 1), which exhibited high toughness and fast self-healing at room temperature without external stimuli [45]. The diblock copolymer comprises an IL-phobic block and a hydrogen bonding block. The IL-phobic block is polystyrene (PS), and the hydrogen bonding block is a statistical copolymer of $N, N$-dimethylacrylamide (DMAAm) and acrylic acid (AAc), which behave as hydrogen bond-accepting and hydrogen bond-donating units, respectively. The diblock copolymer, PS- $b$-P (DMAAm- $r$-AAc), forms a micellar ion gel when combined with an imidazolium-based IL, 1-ethyl-3-methylimidazolium bis(trifluoromethanesulfonyl)amide $\left(\left[\mathrm{C}_{2} \mathrm{mim}\right]\left[\mathrm{NTf}_{2}\right]\right)$. Due to the jammed micelle structure and hydrogen bonding between micelles, the micellar ion gel

\footnotetext{
* Corresponding author. Department of Chemistry and Biotechnology Yokohama National University, 79-5 Tokiwadai, Hodogaya-ku, Yokohama, 240-8501, Japan.

** Corresponding author.

Email addresses: TAMATE.Ryota@nims.go.jp (R. Tamate); mwatanab@ynu.ac.jp (M. Watanabe)
} 


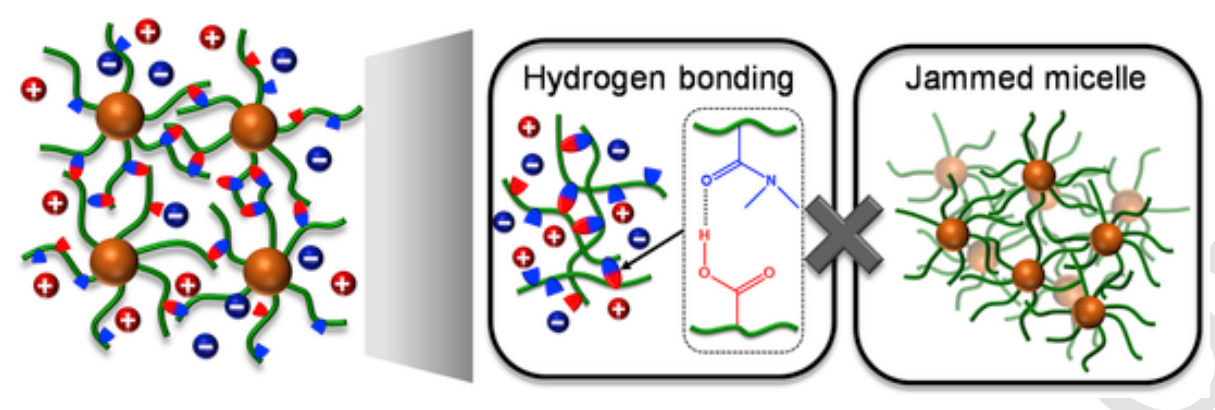

Scheme 1. Conceptual illustration of the micellar ion gel based on micelle jamming and hydrogen bonding.

shows excellent physical properties such as high mechanical strength, good self-standing ability, and rapid self-healing of mechanical and electrochemical properties at room temperature.

However, the effect of the IL cation and anion structures and polymer architectures on the physical properties of the hydrogen-bonded micellar ion gel remain to be investigated. The hydrogen bonding ability of ILs is highly dependent on their cation and anion structures [46], which can therefore modulate the physical properties of the ion gel. Therefore, in this work, the effect of IL cation and anion structures on the microstructure as well as viscoelasticity of a hydrogen-bonded micellar ion gel was investigated in detail.

\section{Experimental}

\subsection{Materials}

The diblock copolymer PS- $b$-P (DMAAm-r-AAc) was synthesized by sequential reversible addition-fragmentation chain transfer (RAFT) polymerization according to our previously reported method [45]. Briefly, a PS-macroinitiator was first synthesized by RAFT polymerization of styrene with $S$-1-dodecyl- $S^{\prime}$-( $\alpha, \alpha^{\prime}$-dimethyl- $\alpha$ "-acetic acid)-trithiocarbonate (purchased from Trylead Chemical Technology, China) as a chain transfer agent. Then, the PS- $b$-P (DMAAm-r-AAc) diblock copolymer was synthesized through RAFT copolymerization of DMAAm and AAc with PS-macroinitiator. $\left[\mathrm{C}_{2} \mathrm{mim}\right]\left[\mathrm{NTf}_{2}\right]$, 1-hexyl-3-methylimidazolium ([ $\left.\left.\mathrm{C}_{6} \mathrm{mim}\right]\right)\left[\mathrm{NTf}_{2}\right]$, 1-ethyl-2,3-dimethylimidazolium ( $\left.\left[\mathrm{C}_{2} \mathrm{dmim}\right]\right)$ $\left[\mathrm{NTf}_{2}\right]$, and $\left[\mathrm{C}_{2} \mathrm{mim}\right]$ methylphosphonate ([MP]) were purchased from Kanto Chemical (Japan). 1-Butyl-3-methylimidazolium ([ $\left.\left.\mathrm{C}_{4} \mathrm{mim}\right]\right)$ $\left[\mathrm{NTf}_{2}\right]$ was purchased from Tokyo Chemical Industry (Japan). Other chemicals were purchased from Wako Pure Chemicals (Japan) and used as received unless noted otherwise.

\subsection{Polymer characterization}

Prior to polymer characterization, the AAc unit in the PS- $b-\mathrm{P}$ (DMAAm-r-AAc) diblock copolymer was methylated using trimethylsilyl diazomethane to avoid irreversible adsorption onto substrates in the chromatography columns $[45,47]$. The polydispersity index (PDI) of the block copolymers was evaluated by gel permeation chromatography (GPC). The columns were calibrated with PS standards, and THF was used as the eluent. The polymerization degree of the PS block was calculated using GPC measurements for the PS macroinitiator. The polymerization degrees of DMAAm and AAc segments were calculated from ${ }^{1} \mathrm{H}$ NMR measurements.

\subsection{Preparation of ion gels}

Ion gels were prepared through a conventional cosolvent method. First, block copolymers and ILs were weighed and dissolved in a mixture of methanol and dichloromethane $(50 / 50 \mathrm{vol} \%)$ at an elevated temperature. Then, the mixed solvent was evaporated at room temperature overnight. The ion gel was further dried under vacuum at $70^{\circ} \mathrm{C}$.

\subsection{Fourier transform infrared (FT-IR) spectroscopy}

Attenuated total reflection Fourier transform infrared (ATR-FT-IR) spectroscopy of ion gels was performed on a Nicolet iS50 FT-IR spectrometer (Thermo Fisher Scientific, MA, USA) equipped with a germanium internal-reflection element. All ATR-FT-IR measurements were performed under dry-air conditions at room temperature.

\subsection{Rheological measurements}

Rheological properties of ion gels were investigated by an Anton Paar Physica MCR 301 rheometer (Anton Paar, Austria). A 25-mm parallel plate geometry with a gap spacing of $0.2 \mathrm{~mm}$ was used for the measurements. For temperature sweep tests, ion gels were equilibrated at $120^{\circ} \mathrm{C}$ for over $10 \mathrm{~min}$ prior to the measurements. Then, the sample was cooled from $120^{\circ} \mathrm{C}$ to $20^{\circ} \mathrm{C}$ at a cooling rate of $1^{\circ} \mathrm{C} / \mathrm{min}$ with a frequency of $1 \mathrm{rad} / \mathrm{s}$ and a strain amplitude of $1 \%$. Frequency sweep measurements were conducted over a frequency range of $0.1-100 \mathrm{rad} / \mathrm{s}$ with a strain amplitude of $1 \%$ at constant temperatures. Time-temperature superposition (tTS) master curves were constructed for the ion gels using the frequency sweep data at different temperatures by employing the tTS principle.

\subsection{Small-angle X-ray scattering (SAXS) measurements}

Small-angle X-ray scattering (SAXS) measurements were conducted on a BL-6A (Photon Factory, Japan). A monochromated X-ray beam (wavelength, $\lambda=1.50 \AA$ ) was used to irradiate the ion gels (thickness: approx. $1 \mathrm{~mm}$ ). The temperature of the ion gel was set at $25^{\circ} \mathrm{C}$ using a hot stage (Instec, Inc., CO, USA). The exposure time was $30 \mathrm{~s}$ for all samples. The scattered X-rays were measured using a detector (PILATUS3 $2 \mathrm{M}$, Dectris, Switzerland) with a sample-to-detector distance of $1.0 \mathrm{~m}$. The obtained 2D data were circularly averaged and corrected by the exposure time, dark current, background scattering, and transmittance.

The Percus-Yevick hard sphere model, which takes the size distribution of the micelle cores into account, was used to analyze the SAXS profiles of the ion gels, according to previous reports $[41,45,48]$. Profiles were fitted by six parameters: $C_{1}, C_{2},\left\langle R_{\mathrm{c}}>, \sigma_{\mathrm{R}}, R_{\mathrm{HS}}\right.$, and $\varphi$, where $C_{1}$ and $C_{2}$ are arbitrary scaling parameters, $\left\langle R_{\mathrm{c}}\right\rangle$ is the average radius of the micelle core, $\sigma_{\mathrm{R}}$ is the standard deviation of the core radius, $R_{\mathrm{HS}}$ is the radius of the fictitious hard sphere, and $\varphi$ is the volume fraction of the fictitious hard sphere.

\section{Results and discussion}

The diblock copolymer, PS-b-P (DMAAm-r-AAc), was synthesized by RAFT polymerization according to our previously reported method (Fig. 1a) [45]. In this study, two diblock copolymers SDA $(8 / 2)$ and SDA $(9 / 1)$ with different DMAAm:AAc ratios were prepared by chang- 
a

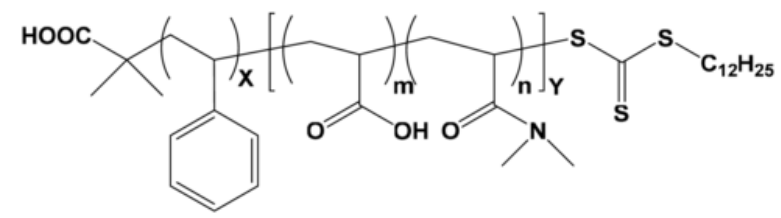

b

\begin{tabular}{|c|c|c|c|}
\hline & Abbreviation & Cation & Anion \\
\hline 1 & {$\left[\mathrm{C}_{2} \mathrm{mim}\right]\left[\mathrm{NTf}_{2}\right]$} & & \\
\hline 2 & {$\left[\mathrm{C}_{4} \mathrm{mim}\right]\left[\mathrm{NTf}_{2}\right]$} & & \\
\hline 3 & {$\left[\mathrm{C}_{6} \mathrm{mim}\right]\left[\mathrm{NTf}_{2}\right]$} & & \\
\hline 4 & {$\left[\mathrm{C}_{2} \mathrm{dmim}\right]\left[\mathrm{NTf}_{2}\right]$} & & \\
\hline 5 & {$\left[\mathrm{C}_{2} \mathrm{mim}\right][\mathrm{MP}]$} & & \\
\hline
\end{tabular}

Fig. 1. (a) Chemical structure of the PS- $b$-P (DMAAm-r-AAc) diblock copolymer. (b) Cation and anion structures and abbreviations of ILs used in this study.

ing the monomer feed ratio (Table 1). The diblock copolymer was combined with five imidazolium-based ILs with different cation and anion structures (Fig. 1b). The melting temperature $\left(T_{\mathrm{m}}\right)$, glass transition temperature $\left(T_{\mathrm{g}}\right)$, and Kamlet-Taft $\alpha, \beta$, and $\pi^{*}$ parameters obtained from literature are summarized in Table S1. The Kamlet-Taft $\alpha$ and $\beta$ parameters are measures of hydrogen bond-donating and hydrogen bond-accepting abilities, respectively, whereas the $\pi^{*}$ parameter represents dipolarity/polarizability [49]. The ILs with different alkyl chain lengths- $\left[\mathrm{C}_{\mathrm{n}} \mathrm{mim}\right]\left[\mathrm{NTf}_{2}\right](\mathrm{n}=2,4,6)$ - showed similar values for $T_{\mathrm{m}}$, $T_{\mathrm{g}}$, and Kamlet-Taft $\alpha, \beta$ and $\pi^{*}$ parameters. However, it is known that nanostructures as well as cohesive energies of these imidazolium-based ILs differ depending on the alkyl chain length [50-53]. The C2 proton of the imidazolium cation has been reported to exhibit relatively strong hydrogen bond-donating ability [54,55]. Therefore, owing to methyl capping of the $\mathrm{C} 2$ position, $\left[\mathrm{C}_{2} \mathrm{dmim}\right]\left[\mathrm{NTf}_{2}\right]$ showed a lower $\alpha$ value than those of $\left[\mathrm{C}_{\mathrm{n}} \mathrm{mim}\right]\left[\mathrm{NTf}_{2}\right](\mathrm{n}=2,4,6)$. In addition to the cation structure, of course, the anion structure of ILs strongly influences their hydrogen bonding ability. In particular, ILs containing strongly hydro-

Table 1

Characterization of the synthesized diblock polymers.

\begin{tabular}{llllll}
\hline Sample & $N_{\text {PS }}{ }^{\mathrm{a}}$ & $N_{\text {PDMAAm }}{ }^{\mathrm{b}}$ & $N_{\text {PAAc }}{ }^{\mathrm{b}}$ & [DMAAm]:[AAc $^{\mathrm{c}}$ & PDI $^{\mathrm{d}}$ \\
\hline SDA (8/2) & 86 & 428 & 103 & $81: 19$ & 1.38 \\
SDA (9/1) & 86 & 558 & 70 & $89: 11$ & 1.35
\end{tabular}

a Degree of polymerization $\left(N_{\mathrm{PS}}\right)$ of the PS block determined by GPC measurements for the PS macroinitiator.

b Degrees of polymerization of DMAAm $\left(N_{\text {PDMAAm }}\right)$ and AAc $\left(N_{\text {PAAc }}\right)$ units in the P (DMAAm-r-AAc) block calculated using ${ }^{1} \mathrm{H}$ NMR data.

c Copolymerization ratio of DMAAm and AAc.

d PDI of each polymer determined by GPC. gen bond-accepting anions such as $\mathrm{Cl}^{-}$and $\mathrm{CH}_{3} \mathrm{CO}_{2}{ }^{-}$have been studied intensively as solvents for poorly soluble biopolymers such as cellulose [56-58]. In this study, $\left[\mathrm{C}_{2} \mathrm{mim}\right.$ ] [MP] (MP: methyl phosphonate), which showed a strong hydrogen bond-accepting ability [59], was chosen to investigate the effect of the anion structure on the physical properties of ion gels. The viscoelastic properties and microstructures of the resulting ion gels formed by combining the imidazolium-based ILs with the PS-b-P (DMAAm- $r$-AAc) diblock copolymer were studied in detail.

$30 \mathrm{wt} \%$ SDA (8/2) ion gels were prepared thorough a cosolvent method: the diblock copolymers and ILs were dissolved in a 1:1 v/v mixture of methanol and dichloromethane, following complete removal of the cosolvent. Fig. 2a shows a photograph of the five ion gels including different ILs. Transparent ion gels were obtained for $\left[\mathrm{C}_{n} \operatorname{mim}\right]\left[\mathrm{NTf}_{2}\right]$ ( $\mathrm{n}=2,4,6)$ - and $\left[\mathrm{C}_{2} \mathrm{mim}\right][\mathrm{MP}]$-based ion gels. On the other hand, an opaque and fragile ion gel was obtained for $\left[\mathrm{C}_{2} \mathrm{dmim}\right]\left[\mathrm{NTf}_{2}\right]$. All ion gels were stable over several weeks at room temperature. The first four ion gels showed single glass transition temperatures at temperatures of around -70 to $-80^{\circ} \mathrm{C}$ in the differential scanning calorimetry (DSC) curve, whereas a melting point, corresponding to melting of the IL, was observed at around $25^{\circ} \mathrm{C}$ for the ion gel with $\left[\mathrm{C}_{2} \mathrm{dmim}\right]\left[\mathrm{NTf}_{2}\right]$ (Fig. 2b). Based on the photograph and the DSC curve, it was suggested that macroscopic phase separation of an IL-rich phase from the polymer-rich micellar network occurred for the $\left[\mathrm{C}_{2} \mathrm{dmim}\right]\left[\mathrm{NTf}_{2}\right]$-based ion gel. In contrast, single glass transition temperatures and their transparent appearances indicated percolating micellar networks formed for the other ion gels without macroscopic phase separation.

Rheological properties of ion gels were investigated by temperature sweep measurements. Fig. 3a compares temperature-dependent vis-

a
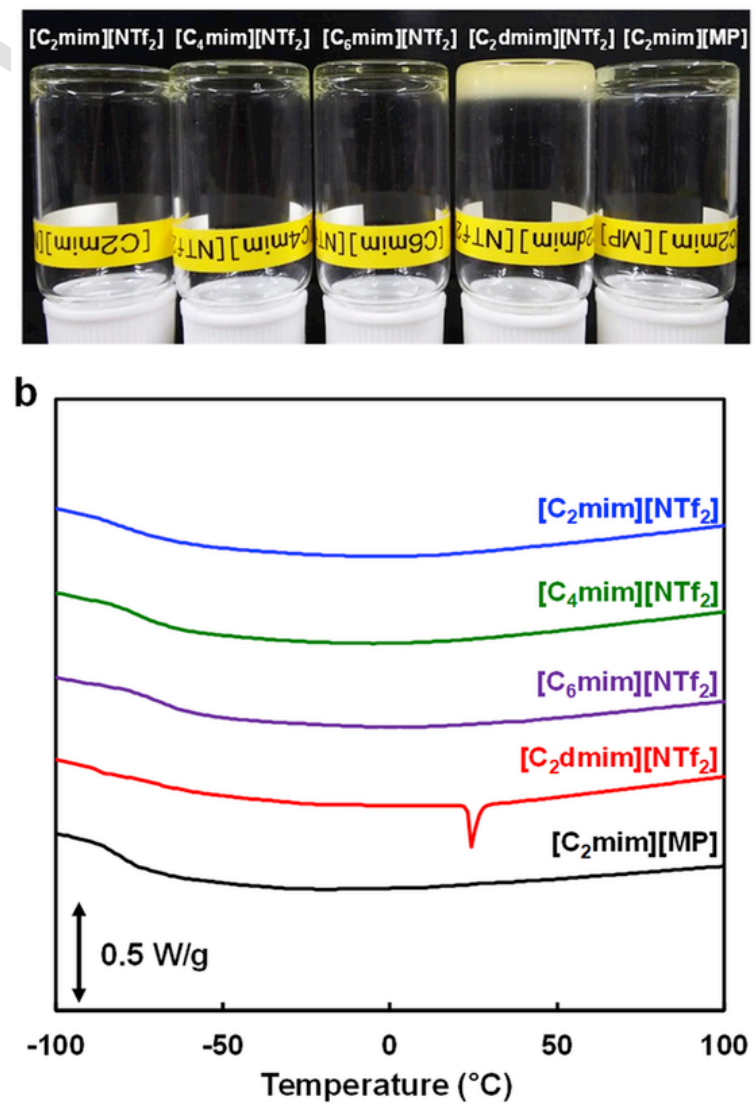

Fig. 2. (a) Photograph for $30 \mathrm{wt} \%$ SDA (8/2) ion gels with five different ILs. (b) DSC curves for ion gels (heating rate: $10^{\circ} \mathrm{C} / \mathrm{min}$ ). 


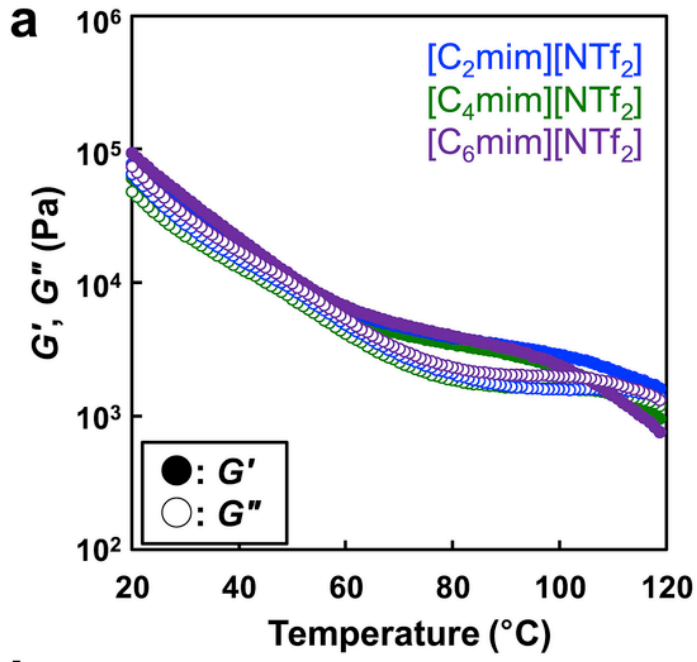

b

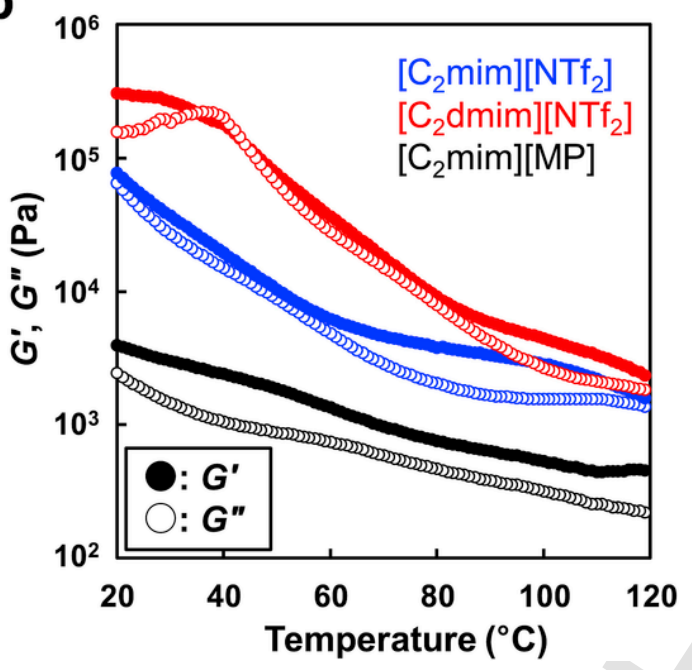

Fig. 3. Temperature dependence of $G^{\prime}$ (closed symbols) and $G^{\prime \prime}$ (open symbols) of $30 \mathrm{wt} \%$ SDA (8/2) ion gels with five different ILs at a frequency of $1 \mathrm{rad} / \mathrm{s}$, a strain amplitude of $1 \%$, and a cooling rate of $1{ }^{\circ} \mathrm{C} / \mathrm{min}$ : (a) $\left[\mathrm{C}_{n} \operatorname{mim}\right]\left[\mathrm{NTf}_{2}\right]$-based ion gels $(\mathrm{n}=2,4,6)$. (b) $\left[\mathrm{C}_{2} \mathrm{mim}\right]\left[\mathrm{NTf}_{2}\right],\left[\mathrm{C}_{2} \mathrm{dmim}\right]\left[\mathrm{NTf}_{2}\right]$, and $\left[\mathrm{C}_{2} \mathrm{mim}\right][\mathrm{MP}]$-based ion gels.

coelastic behaviors of ion gels containing imidazolium cations with different alkyl chain lengths $\left(\left[\mathrm{C}_{\mathrm{n}} \mathrm{mim}\right]\left[\mathrm{NTf}_{2}\right], \mathrm{n}=2,4,6\right)$. Storage $\left(G^{\prime}\right)$ and loss $\left(G^{\prime \prime}\right)$ moduli for the three ion gels exhibited similar temperature dependence. At low temperatures, these ion gels showed high $G^{\prime}$ and $G^{\prime \prime}$ values. Although $G^{\prime}$ was larger than $G^{\prime \prime}$, the orders of magnitude of $G^{\prime}$ and $G^{\prime \prime}$ values were comparable. This could be attributed to the strong and dissipative nature of the hydrogen bonding between coronal chains of micelles. At high temperatures, on the other hand, $G^{\prime}$ and $G^{\prime \prime}$ decreased due to weakened hydrogen bonding. However, these ion gels maintained the gel state $\left(G^{\prime}>G^{\prime \prime}\right)$ over a wide temperature range, which could be attributed to the jamming of diblock copolymer micelles in ILs. This was evidenced by the observation that ion gels formed by the P (DMAAm-r-AAc) copolymer showed liquid-like behavior $\left(G^{\prime}<G^{\prime \prime}\right)$ at a much lower temperature, as we reported previously [45]. The similar temperature dependence of $G^{\prime}$ and $G^{\prime \prime}$ for three ion gels containing $\left(\left[\mathrm{C}_{\mathrm{n}} \mathrm{mim}\right]\left[\mathrm{NTf}_{2}\right](\mathrm{n}=2,4,6)\right.$ indicates that the alkyl chain length of the imidazolium cation does not have a significant effect on the viscoelastic behavior of the hydrogen-bonded micellar ion gel. This could be because these ILs have similar hydrogen bonding abilities (Table S1). On the other hand, Fig. 3b compares ion gels with $\left[\mathrm{C}_{2} \mathrm{mim}\right]\left[\mathrm{NTf}_{2}\right],\left[\mathrm{C}_{2} \mathrm{dmim}\right]\left[\mathrm{NTf}_{2}\right]$ and $\left[\mathrm{C}_{2} \mathrm{mim}\right][\mathrm{MP}]$, revealing the drastic differences in their viscoelasticity. The ion gel including
$\left[\mathrm{C}_{2} \mathrm{dmim}\right]\left[\mathrm{NTf}_{2}\right]$ exhibited much higher $G^{\prime}$ and $G^{\prime \prime}$ values than those of the ion gels with $\left[\mathrm{C}_{2} \mathrm{mim}\right]\left[\mathrm{NTf}_{2}\right]$. This result demonstrates that the decrease in the hydrogen bond-donating ability of the imidazolium cation owing to methyl capping of the C2 position significantly affects the viscoelasticity of the ion gel. As the hydrogen bond interaction between the $\left[\mathrm{C}_{2} \mathrm{dmim}\right]$ cation and the hydrogen bond-accepting DMAAm unit in the diblock copolymer was weak, the intermicellar (inter-coronal chain) hydrogen bonding was enhanced, resulting in macroscopic phase separation and increased $G^{\prime}$ and $G^{\prime \prime}$ values. On the other hand, when the $\left[\mathrm{NTf}_{2}\right]$ anion of the $\left[\mathrm{C}_{2} \mathrm{mim}\right]\left[\mathrm{NTf}_{2}\right]$ was replaced by the $[\mathrm{MP}]$ anion, which had a strong hydrogen bond-accepting ability, $G^{\prime}$ and $G^{\prime \prime}$ values became much lower than those of the $\left[\mathrm{C}_{2} \mathrm{mim}\right]\left[\mathrm{NTf}_{2}\right]$-based ion gel. This suggests that strong hydrogen bonding between the [MP] anion and the hydrogen bond-donating AAc unit interrupts the hydrogen bonding between DMAAm and AAc units. Thus, not only the hydrogen boding ability of the cation of ILs, but the anion structure also has a great impact on the ion gel viscoelasticity.

The hydrogen bonding between the diblock copolymer and the [MP] anion could be clearly confirmed by ATR-FT-IR spectroscopy (Fig. 4). Carbonyl stretching bands of the DMAAm and AAc units were observed at wavelengths of around $1635 \mathrm{~cm}^{-1}$ and $1725 \mathrm{~cm}^{-1}$, respectively. When hydrogen bonding existed between DMAAm and AAc, peak shifts occurred for the carbonyl stretching bands [45,60,61]. Consistent with previous reports, the peak shift of the carbonyl stretching peak of DMAAm to a lower wavelength of around $1605 \mathrm{~cm}^{-1}$ was observed for ion gels with $\left[\mathrm{C}_{\mathrm{n}} \mathrm{mim}\right]\left[\mathrm{NTf}_{2}\right](\mathrm{n}=2,4,6)$ and $\left[\mathrm{C}_{2} \mathrm{dmim}\right]\left[\mathrm{NTf}_{2}\right]$, indicating hydrogen bonding between DMAAm and AAc units in ILs. Remarkably, for the $\left[\mathrm{C}_{2} \mathrm{mim}\right][\mathrm{MP}]$-based ion gel, the shifted carbonyl stretching peak of DMAAm around $1605 \mathrm{~cm}^{-1}$ was not observed, and the carbonyl stretching band of the AAc unit showed a significant shift. This implies that the hydrogen bonding between DMAAm and AAc units was significantly suppressed by hydrogen bonding between the [MP] anion and the carboxylic proton of the AAc unit, which is consistent with the much lower $G^{\prime}$ and $G^{\prime \prime}$ values of the $\left[\mathrm{C}_{2} \mathrm{mim}\right][\mathrm{MP}]$-based ion gel than those of other four ion gels shown in Fig. 3 .

Rheological properties of the SDA (8/2) ion gels were further investigated by constructing time-temperature superposition (tTS) master curves for $G^{\prime}$ and $G^{\prime \prime}$ as function of the frequency against a reference temperature of $50^{\circ} \mathrm{C}$ (Fig. 5). The tTS master curve was obtained from frequency sweep measurements at a constant temperature from 20 to $120^{\circ} \mathrm{C}$ in $10^{\circ} \mathrm{C}$ steps. For ion gels including $\left[\mathrm{C}_{\mathrm{n}} \mathrm{mim}\right]\left[\mathrm{NTf}_{2}\right](\mathrm{n}=2,4$, 6), similar frequency dependence was observed for $G^{\prime}$ and $G^{\prime \prime}$, which

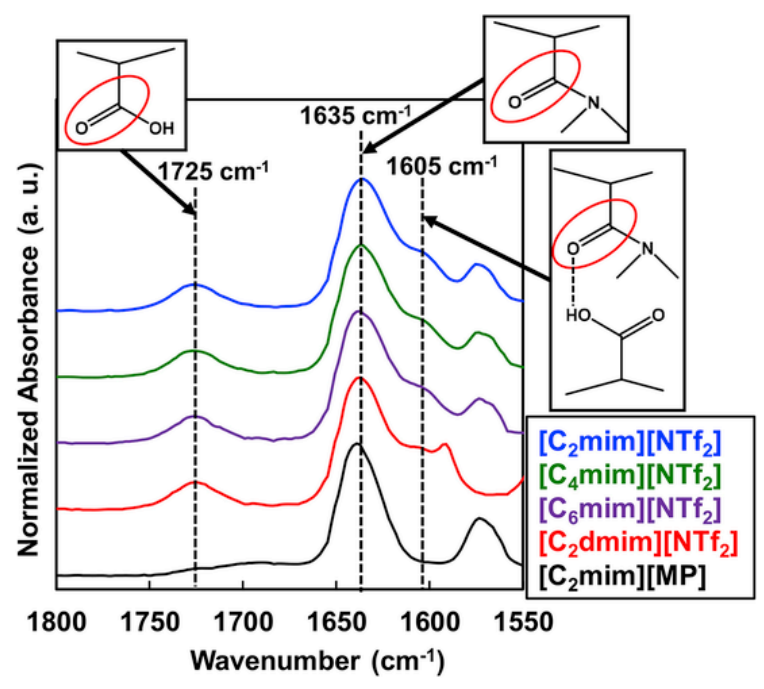

Fig. 4. ATR-FT-IR spectra for $30 \mathrm{wt} \%$ SDA (8/2) ion gels with five different ILs. 

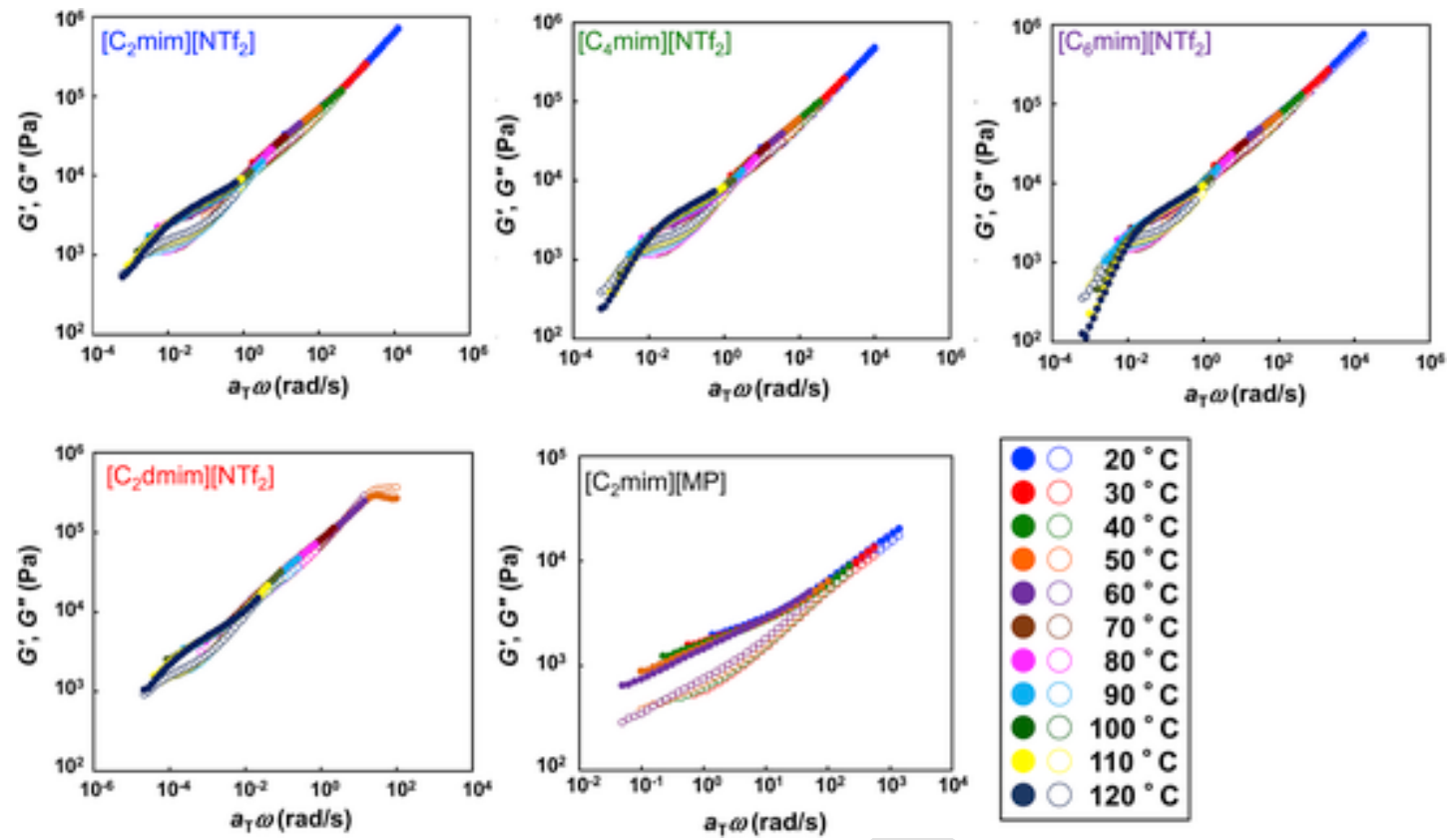

Fig. 5. tTS master curves for $G^{\prime}$ (closed symbols) and $G^{\prime \prime}$ (open symbols) of $30 \mathrm{wt} \%$ SDA (8/2) ion gels with five different ILs. The reference temperature is $50^{\circ} \mathrm{C}$.

was consistent with results shown in Fig. 3a. In the low-frequency region, however, a slight difference was observed. Onset of a terminal flow behavior was observed for ion gels with $\left[\mathrm{C}_{4} \mathrm{mim}\right]\left[\mathrm{NTf}_{2}\right]$ and $\left[\mathrm{C}_{6} \mathrm{mim}\right]\left[\mathrm{NTf}_{2}\right]$, but not observed for the one with $\left[\mathrm{C}_{2} \mathrm{mim}\right]\left[\mathrm{NTf}_{2}\right]$ at this measurement range. The crossover frequency at which $G^{\prime}$ and $G^{\prime \prime}$ became equal followed the order $\left[\mathrm{C}_{6} \mathrm{mim}\right]\left[\mathrm{NTf}_{2}\right]>\left[\mathrm{C}_{4} \mathrm{mim}\right]\left[\mathrm{NTf}_{2}\right]>\left[\mathrm{C}_{2} \mathrm{mim}\right]\left[\mathrm{NTf}_{2}\right]$. The reason for this is unclear now, but one possibility is that the long alkyl chain in the imidazolium cation can plasticize the PS micelle core, which leads to disassembly of the PS core in the low-frequency (or high-temperature) region. Another possible reason could be that accelerated nanoscale segregation of the alkyl chains of imidazolium cations with long alkyl chain lengths might enhance the interaction between the ionic part of the imidazolium cation and the polymer chain. Consistent with the temperature sweep measurements, the ion gel including $\left[\mathrm{C}_{2} \mathrm{dmim}\right]\left[\mathrm{NTf}_{2}\right]$ showed higher $G^{\prime}$ and $G^{\prime \prime}$ values than those of other ion gels at the same frequency. The tTS principle was not applicable for the $\left[\mathrm{C}_{2} \mathrm{dmim}\right]\left[\mathrm{NTf}_{2}\right]$-based ion gel at low temperatures, possibly owing to the melting transition of the phase-separated $\left[\mathrm{C}_{2} \mathrm{dmim}\right]\left[\mathrm{NTf}_{2}\right]$-rich region (Fig. 2b). The rheological response of the $\left[\mathrm{C}_{2} \mathrm{mim}\right][\mathrm{MP}]$-based ion gel was drastically different from that of other ion gels, and tTS failed at high temperatures (The overall master curve can be seen in Fig. S1). This implies that the origin of the viscoelasticity of the $\left[\mathrm{C}_{2} \mathrm{mim}\right][\mathrm{MP}]$-based ion gel changed at high temperatures.

The Arrhenius plot for the shift factor $\left(a_{\mathrm{T}}\right)$ of five ion gels is shown in Fig. 6a. For $\left[\mathrm{C}_{2} \mathrm{dmim}\right]\left[\mathrm{NTf}_{2}\right]-$ and $\left[\mathrm{C}_{2} \mathrm{mim}\right][\mathrm{MP}]$-based ion gels, $a_{\mathrm{T}}$ values at a temperature range where the tTS principle was applicable were plotted. An apparent activation energy $\left(E_{\mathrm{a}}\right)$ of these ion gels (Fig. S2a and Table S2) was obtained by applying the Arrhenius equation, $a_{\mathrm{T}}=A \exp \left(E_{\mathrm{a}} / R T\right)$, where $A$ is a constant and $R$ is the ideal gas constant (Fig. 6b). The magnitudes of $E_{\mathrm{a}}$ followed the order $\left[\mathrm{C}_{2} \mathrm{dmim}\right]\left[\mathrm{NTf}_{2}\right]>\left[\mathrm{C}_{2} \mathrm{mim}\right]\left[\mathrm{NTf}_{2}\right] \sim\left[\mathrm{C}_{4} \mathrm{mim}\right]\left[\mathrm{NTf}_{2}\right] \sim\left[\mathrm{C}_{6} \mathrm{mim}\right]\left[\mathrm{NTf}_{2}\right]>\left[\mathrm{C}_{2} \mathrm{r}\right.$ implying that the apparent activation energy reflects the strength of hydrogen bonding between polymer chains. It should also be noted that the temperature dependence of $a_{\mathrm{T}}$ values for these ion gels can be better fitted by the Vogel-Fulcher-Tammann (VFT) equation, $a_{\mathrm{T}}=A^{\prime}$ exp $\left(B / T-T_{0}\right)$, where $A^{\prime}$ and $B$ are empirical constants and $T_{0}$ is the reference temperature (Fig. S2b and Table a
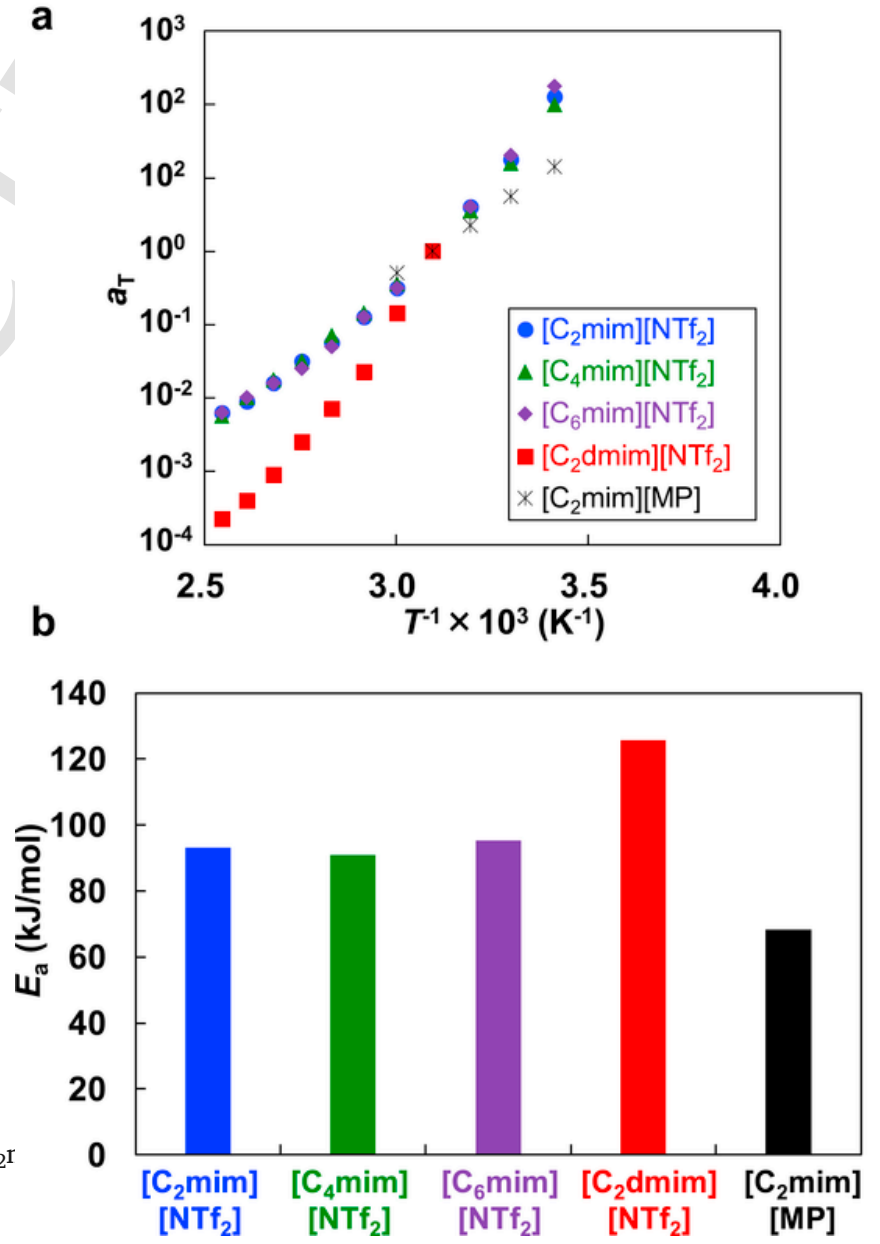

Fig. 6. (a) Arrhenius plots for tTS shift factors $a_{\mathrm{T}}$ of five ion gels including different ILs. (b) Apparent activation energies $\left(E_{\mathrm{a}}\right)$ of ion gels obtained by fitting using the Arrhenius equation. 
S2). Previously, it was reported that polymers containing relatively weakly hydrogen bonding side groups such as AAc followed the VFT equation well, whereas polymers containing relatively strongly hydrogen bonding side groups such as ureidopyrimidinone followed the Arrhenius equation well [62]. In the case of the VFT equation, the empirical term $B$ could be interpreted as a temperature-dependent activation energy. The order of the magnitude of the $B$ is the same as that of $E_{\mathrm{a}}$, suggesting that the constant $B$ is also related to the strength of the hydrogen bonding between polymers (Fig. S3).

The microstructure of the SDA (8/2) ion gels was investigated by small angle X-ray scattering (SAXS) measurements (Fig. 7). All SAXS profiles were well-fitted by the Percus-Yevick hard sphere model $[41,45,48]$, which indicates that the diblock copolymer micelles were randomly located in ILs. The fitting parameters are shown in Table 2. It is noted that volume fractions of fictious hard spheres $(\varphi)$ for five ion

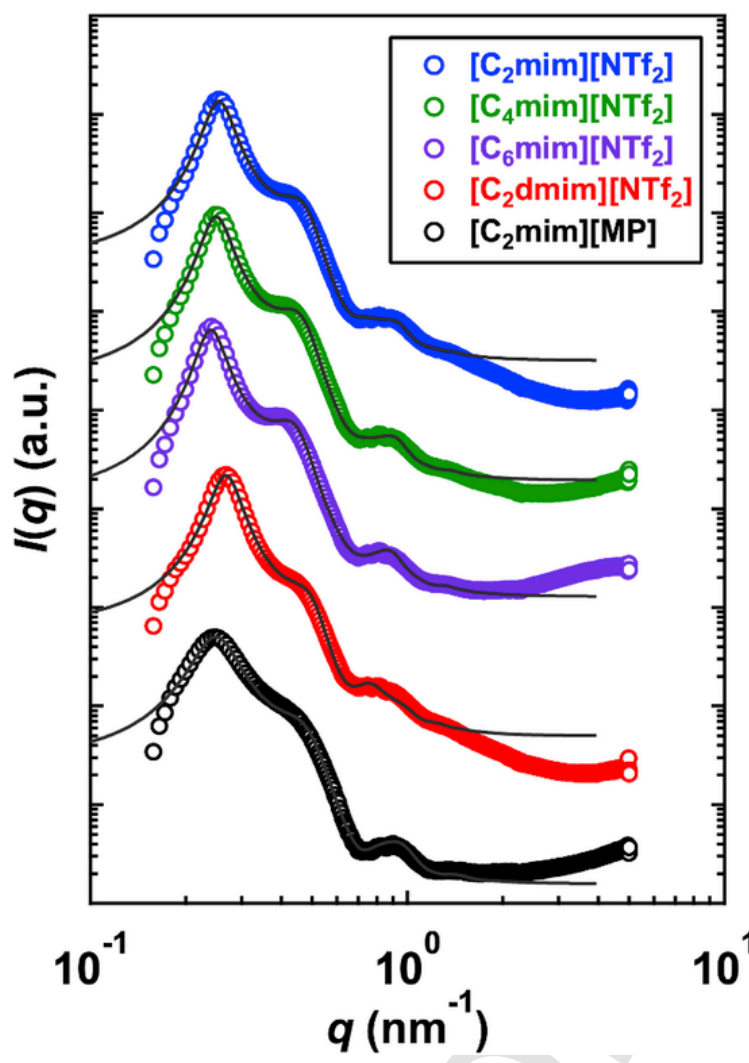

Fig. 7. SAXS profiles for the $30 \mathrm{wt} \%$ SDA (8/2) ion gels with five different ILs. Each solid line corresponds to fitting by the Percus-Yevick hard sphere model.

Table 2

Percus-Yevick fitting parameters for the $30 \mathrm{wt} \%$ SDA (8/2) ion gels with five different ILs.

\begin{tabular}{lllll}
\hline ILs & {$\left[\mathrm{C}_{2} \mathrm{mim}\right]\left[\mathrm{NTf}_{2}\right]$} & {$\left[\mathrm{C}_{4} \mathrm{mim}\right]\left[\mathrm{NTf}_{2}\right]$} & {$\left[\mathrm{C}_{6} \mathrm{mim}\right]\left[\mathrm{NTf}_{2}\right]$} & {$\left[\mathrm{C}_{2} \mathrm{dmim}\right]\left[\mathrm{NTf}_{2}\right]$} \\
\hline$\varphi^{\mathrm{a}}$ & $0.44 \pm 0.01$ & $0.44 \pm 0.01$ & $0.45 \pm 0.01$ & $0.44 \pm 0.01$ \\
$R_{\mathrm{h}}{ }^{\mathrm{b}}$ & $13.2 \pm 0.1$ & $13.5 \pm 0.1$ & $14.1 \pm 0.1$ & $12.5 \pm 0.1$ \\
$(\mathrm{~nm})$ & & $6.28 \pm 0.01$ & $6.41 \pm 0.01$ & $6.37 \pm 0.01$ \\
$\begin{array}{l}<R_{\mathrm{c}}>^{\mathrm{c}} \\
(\mathrm{nm})\end{array}$ & $6.26 \pm 0.01$ & $0.81 \pm 0.01$ & $0.80 \pm 0.01$ & $1.06 \pm 0.01$ \\
$\sigma_{\mathrm{d}}$ & $0.86 \pm 0.01$ & 0.06 \\
\hline
\end{tabular}

a Volume fraction of the fictitious hard sphere.

b Radius of the fictitious hard sphere.

c Average radius of the micelle core.

d Standard deviation of the micelle core radius. gels are smaller than the random close packing limitation $\left(\varphi_{\text {rcp }} \sim 0.64\right)$, which is consistent with our previous study for jammed micelles formed by a thermoresponsive ABC triblock copolymer and ILs [41]. The order of the size of micelle cores is consistent with that obtained by atomic force microscopy [45]. Except the $\left[\mathrm{C}_{2} \mathrm{mim}\right][\mathrm{MP}]$-based one, similar fitting parameter values were obtained for the ion gels, implying that the jammed micelle structure did not change much among these ILs. Although opaque appearance was observed for the $\left[\mathrm{C}_{2} \mathrm{dmim}\right]\left[\mathrm{NTf}_{2}\right]$-based ion gel, its SAXS profile was similar to those of the $\left[\mathrm{C}_{\mathrm{n}} \operatorname{mim}\right]\left[\mathrm{NTf}_{2}\right]$ ( $n=2,4,6$ )-based ion gels. This could be due to the fact that, for the $\left[\mathrm{C}_{2} \mathrm{dmim}\right]\left[\mathrm{NTf}_{2}\right]$-based ion gel, there exist the micellar network-rich phase and IL-rich phase, however, the contribution of the IL-rich phase to the scattering intensity was much lower than that of the micellar network-rich phase, where the jammed micelle structure similar to the $\left[\mathrm{C}_{n} \mathrm{mim}\right]\left[\mathrm{NTf}_{2}\right](\mathrm{n}=2,4,6)$-based ion gels formed. On the other hand, the volume fraction of the fictitious hard sphere $(\varphi)$ for the $\left[\mathrm{C}_{2} \mathrm{mim}\right][\mathrm{MP}]$-based ion gel was lower than that of other ion gels. The reason for the small $\varphi$ value obtained is not clear; however, one possibility is that as the mobility of the diblock copolymer micelle in $\left[\mathrm{C}_{2} \mathrm{mim}\right][\mathrm{MP}]$ was much higher than that in other ILs due to reduced intermicellar hydrogen bonding, the apparent volume fraction of micelles that can be regarded as the fictitious hard sphere might have decreased.

In addition to the differences in the IL cation and anion structures, the effect of the chemical composition of the diblock copolymer was also investigated. Fig. 8a shows DSC curves and images of $30 \mathrm{wt} \%$ SDA $(8 / 2)$ and SDA $(9 / 1)$ ion gels including $\left[\mathrm{C}_{2} \mathrm{dmim}\right]\left[\mathrm{NTf}_{2}\right]$. Notably, the melting temperature of $\left[\mathrm{C}_{2} \mathrm{dmim}\right]\left[\mathrm{NTf}_{2}\right]$ was not observed and a transparent ion gel was obtained for SDA (9/1), indicating that macroscopic phase transition did not occur in the ion gel. Furthermore, viscoelastic properties were significantly different for the SDA (8/2) and SDA (9/1) ion gels (Fig. 8b). These results indicate that decreasing the number of hydrogen bond-donating AAc units reduces hydrogen bond interactions between polymer chains, increasing the compatibility between diblock copolymer micelles and $\left[\mathrm{C}_{2} \mathrm{dmim}\right]\left[\mathrm{NTf}_{2}\right]$. This result also supports the importance of competitive hydrogen bond interactions among IL cations and anions and polymer chains in determining the microstructures and physical properties of the micellar ion gel.

\section{Conclusions}

In this study, the effect of IL cation and anion structures on the microstructure and physical properties of the micellar ion gel formed by micelle jamming and hydrogen bonding was investigated in detail. The PS- $b$-P (DMAAm-r-AAc) diblock copolymer was combined with five ILs containing different cation and anion structures, and the structure-property relationships of the resulting micellar ion gels were investigated in detail. Rheological measurements showed that the hydrogen bonding ability of ILs have a significant impact on the viscoelasticity of the ion gels. When the hydrogen bonding ability of the ILs is relatively strong, such as for $\left[\mathrm{C}_{2} \mathrm{mim}\right][\mathrm{MP}]$, the hydrogen bonding between diblock copolymer micelles is suppressed to a significant extent, resulting in decreased $G^{\prime}$ and $G^{\prime \prime}$ values. On the other hand, when the hydrogen bonding ability of the IL becomes very weak, for example, by methyl capping the $\mathrm{C} 2$ position of the imidazolium cation, hydrogen bonding between diblock copolymer micelles becomes very strong, which results in macroscopic phase separation of an IL-rich phase from a polymer-rich phase. Furthermore, viscoelasticity of the ion gel can be also significantly modulated by changing the ratio of the hydrogen bond-donating and hydrogen bond-accepting units in the hydrogen bonding block. These results suggest that competitive hydrogen bonding among IL cations and anions and polymers is crucial in determining the microstructure as well as physical properties of the micellar ion gel, and they can be controlled finely by judiciously tuning the IL cation and an- 

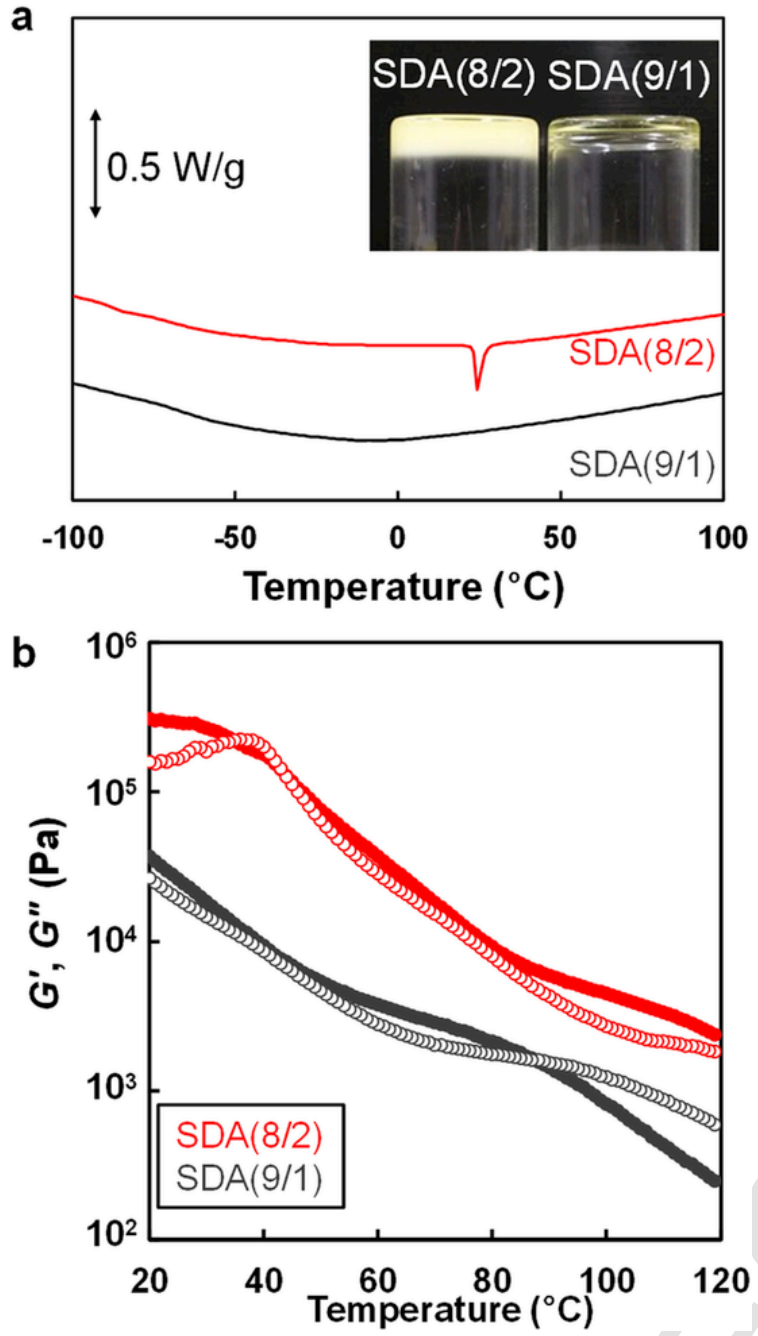

Fig. 8. (a) DSC curves for $30 \mathrm{wt} \%$ SDA (8/2) (red) and SDA (9/1) (black) ion gels with $\left[\mathrm{C}_{2} \mathrm{dmim}\right]\left[\mathrm{NTf}_{2}\right]$. Heating rate: $10^{\circ} \mathrm{C} / \mathrm{min}$. (Inset) Photograph of the SDA $(8 / 2)$ and SDA (9/1) ion gels. (b) Temperature sweep tests for $G^{\prime}$ (closed) and $G^{\prime \prime}$ (open) of the SDA (8/2) and SDA (9/1) ion gels with a frequency of $1 \mathrm{rad} / \mathrm{s}$ and a strain amplitude of $1 \%$ at a cooling rate of $1{ }^{\circ} \mathrm{C} / \mathrm{min}$. (For interpretation of the references to colour in this figure legend, the reader is referred to the Web version of this article.)

ion structures. Further investigation of ILs having various cation and anion structures is necessary to obtain ion gels that exhibit desirable physical properties such as high toughness, self-standing ability and fast self-healability.

\section{Acknowledgement}

This work was financially supported by Grants-in-Aid for Scientific Research (15H05758 to M.W. and 18K14280 to R.T.) and Specially Promoted Research on Iontronics funded by MEXT, Japan. R.T. acknowledges a Research Fellowship awarded by the Japan Society for the Promotion of Science for Young Scientists (17J00756).

\section{Appendix A. Supplementary data}

Supplementary data to this article can be found online at https://doi. org/10.1016/j.polymer.2019.121694.

\section{References}

[1] T.L. Sun, T. Kurokawa, S. Kuroda, A. Bin Ihsan, T. Akasaki, K. Sato, M.A. Haque, T. Nakajima, J.P. Gong, Nat. Mater. 12 (2013) 932-937.

[2] K. Ito, Polym. J. 39 (2007) 489-499.

[3] M. Shibayama, Soft Matter 8 (2012) 8030.

[4] C.W. Peak, J.J. Wilker, G. Schmidt, Colloid Polym. Sci. 291 (2013) 2031-2047.

[5] C. Creton, Macromolecules 50 (2017) 8297-8316.

[6] T. Sakai, T. Matsunaga, Y. Yamamoto, C. Ito, R. Yoshida, S. Suzuki, N. Sasaki, M. Shibayama, U. Chung, Macromolecules 41 (2008) 5379-5384.

[7] H. Kamata, Y. Akagi, Y. Kayasuga-Kariya, U. -i Chung, T. Sakai, Science (80-. ). 343 (2014) 873-875

[8] A.V. Zhukhovitskiy, M. Zhong, E.G. Keeler, V.K. Michaelis, J.E.P. Sun, M.J.A. Hore, D.J. Pochan, R.G. Griffin, A.P. Willard, J.A. Johnson, Nat. Chem. 8 (2015) 33-41.

[9] M.C. Koetting, J.T. Peters, S.D. Steichen, N.A. Peppas, Mater. Sci. Eng. R Rep. 93 (2015) 1-49.

[10] S. Ahn, R.M. Kasi, S.-C. Kim, N. Sharma, Y. Zhou, Soft Matter 4 (2008) 1151-1157.

[11] I. Tokarev, S. Minko, Soft Matter 5 (2009) 511-524.

[12] Y. Qiu, K. Park, Adv. Drug Deliv. Rev. 64 (2012) 49-60.

[13] R. Tamate, A. Mizutani Akimoto, R. Yoshida, Chem. Rec. 16 (2016) 1852-1867.

[14] Y.S. Kim, R. Tamate, A.M. Akimoto, R. Yoshida, Mater. Horiz. 4 (2017) 38-54.

[15] L. Heinen, A. Walther, Soft Matter 11 (2015) 7857-7866.

[16] J.L. Drury, D.J. Mooney, Biomaterials 24 (2003) 4337-4351.

[17] E. Soussan, S. Cassel, M. Blanzat, I. Rico-Lattes, Angew. Chem. Int. Ed. 48 (2009) 274-288.

[18] M.W. Tibbitt, K.S. Anseth, Biotechnol. Bioeng. 103 (2009) 655-663.

[19] J. Thiele, Y. Ma, S.M.C. Bruekers, S. Ma, W.T.S. Huck, Adv. Mater. 26 (2014) $125-148$.

[20] A.S. Hoffman, Adv. Drug Deliv. Rev. 64 (2012) 18-23.

[21] M. Suzuki, Y. Nakajima, M. Yumoto, M. Kimura, H. Shirai, K. Hanabusa, Lang muir 19 (2003) 8622-8624.

[22] D.R. Trivedi, P. Dastidar, Chem. Mater. 18 (2006) 1470-1478.

[23] S.R. Jadhav, P.K. Vemula, R. Kumar, S.R. Raghavan, G. John, Angew. Chem. Int. Ed. 49 (2010) 7695-7698.

[24] S. Basak, J. Nanda, A. Banerjee, J. Mater. Chem. 22 (2012) 11658-11664.

[25] A. Vidyasagar, K. Handore, K.M. Sureshan, Angew. Chem. Int. Ed. 50 (2011) 8021-8024.

[26] M. Suzuki, K. Hanabusa, Chem. Soc. Rev, 39 (2010) 455-463.

[27] A. Manuel Stephan, Eur. Polym. J. 42 (2006) 21-42.

[28] X. Cheng, J. Pan, Y. Zhao, M. Liao, H. Peng, Adv. Energy Mater. 8 (2018) 1702184

[29] S. Liang, W. Yan, X. Wu, Y. Zhang, Y. Zhu, H. Wang, Y. Wu, Solid State Ion. 318 (2018) 2-18.

[30] Y. Shi, J. Zhang, L. Pan, Y. Shi, G. Yu, Nano Today 11 (2016) 738-762.

[31] A. Vintiloiu, J.-C. Leroux, J. Control. Release 125 (2008) 179-192.

[32] T. Ueki, M. Watanabe, Macromolecules 41 (2008) 3739-3749.

[33] J. Le Bideau, L. Viau, A. Vioux, Chem. Soc. Rev. 40 (2011) 907-925.

[34] N. Chen, H. Zhang, L. Li, R. Chen, S. Guo, Adv. Energy Mater. 8 (2018) 1702675.

[35] E. Kamio, T. Yasui, Y. Iida, J.P. Gong, H. Matsuyama, Adv. Mater. 29 (2017) 1704118 .

[36] T.P. Lodge, Science (80-. ). 321 (2008) 50-51.

[37] T.P. Lodge, T. Ueki, Acc. Chem. Res. 49 (2016) 2107-2114.

[38] R. Tamate, K. Hashimoto, T. Ueki, M. Watanabe, Phys. Chem. Chem. Phys. 20 (2018) 25123-25139.

[39] Y. He, T.P. Lodge, Chem. Commun. (2007) 2732.

[40] A. Noro, Y. Matsushita, T.P. Lodge, Macromolecules 41 (2008) 5839-5844.

[41] Y. Kitazawa, T. Ueki, L.D. McIntosh, S. Tamura, K. Niitsuma, S. Imaizumi, T.P. Lodge, M. Watanabe, Macromolecules 49 (2016) 1414-1423.

[42] R. Tamate, R. Usui, K. Hashimoto, Y. Kitazawa, H. Kokubo, M. Watanabe, Soft Matter 14 (2018) 9088-9095.

[43] X. Ma, R. Usui, Y. Kitazawa, R. Tamate, H. Kokubo, M. Watanabe, Macromolecules 50 (2017) 6788-6795.

[44] T. Ueki, Y. Nakamura, R. Usui, Y. Kitazawa, S. So, T.P. Lodge, M. Watanabe, Angew. Chem. Int. Ed. 54 (2015) 3018-3022.

[45] R. Tamate, K. Hashimoto, T. Horii, M. Hirasawa, X. Li, M. Shibayama, M. Watanabe, Adv. Mater. 30 (2018) 1802792.

[46] K. Dong, S. Zhang, J. Wang, Chem. Commun. 52 (2016) 6744-6764.

[47] S. Graham, P.A.G. Cormack, D.C. Sherrington, Macromolecules 38 (2005) $86-90$.

[48] D.J. Kinning, E.L. Thomas, Macromolecules 17 (1984) 1712-1718.

[49] C. Reichardt, Green Chem. 7 (2005) 339.

[50] J.N.A. Canongia Lopes, A.A.H. Pádua, J. Phys. Chem. B 110 (2006) 3330-3335.

[51] L.M.N.B.F. Santos, J.N. Canongia Lopes, J.A.P. Coutinho, J.M.S.S. Esperança, L.R. Gomes, I.M. Marrucho, L.P.N. Rebelo, J. Am. Chem. Soc. 129 (2007) 284-285.

[52] A. Triolo, O. Russina, H.-J. Bleif, E. Di Cola, J. Phys. Chem. B 111 (2007) 4641-4644.

[53] R. Hayes, G.G. Warr, R. Atkin, Chem. Rev. 115 (2015) 6357-6426.

[54] J.M. Crosthwaite, S.N.V.K. Aki, E.J. Maginn, J.F. Brennecke, J. Phys. Chem. B 108 (2004) 5113-5119.

[55] P.A. Hunt, J. Phys. Chem. B 111 (2007) 4844-4853. 
[56] R.P. Swatloski, S.K. Spear, J.D. Holbrey, R.D. Rogers, J. Am. Chem. Soc. 124 (2002) 4974-4975.

[57] S. Zhu, Y. Wu, Q. Chen, Z. Yu, C. Wang, S. Jin, Y. Ding, G. Wu, Green Chem. 8 (2006) 325.

[58] M.E. Zakrzewska, E. Bogel-Łukasik, R. Bogel-Łukasik, Energy Fuels 24 (2010) 737-745.
[59] Y. Fukaya, K. Hayashi, M. Wada, H. Ohno, Green Chem. 10 (2008) 44-46.

[60] T. Shibanuma, T. Aoki, K. Sanui, N. Ogata, A. Kikuchi, Y. Sakurai, T. Okano, Macromolecules 33 (2000) 444-450.

[61] A.S. Hadj-Hamou, S. Djadoun, J. Appl. Polym. Sci. 103 (2007) 1011-1024.

[62] C.L. Lewis, K. Stewart, M. Anthamatten, Macromolecules 47 (2014) 729-740. 